\title{
Foreword
}

\section{Timothy O’Shea}

This book was produced to mark the Computers and Learning research group's fortieth year. The CALRG, as it is known, has a special place in the history of The Open University. When it was established back in 1978, The Open University was still young, and only in its eighth year of the innovative teaching of students at a distance.

From the outset there was a recognition of the potential of the computer to assist and enrich our students' experience of being distance learners. In 1975 we offered remedial tutorial Computer Assisted Learning (with feedback) via terminals in study centres, simulations at science summer schools and day schools and a specially designed programming language to help psychology students construct cognitive models.

The folk who came together in 1978 to form this very interdisciplinary research group understood that we had to make effective use of these newly developing technologies and we were very ambitious. We wanted to develop a research group that would cross faculty boundaries and be world leading. The Open University is the twentieth century's greatest educational experiment. As such the group saw it could be considered as a test bed with which to explore all the possible ways that the quality of student learning could be impacted by the judicious and imaginative use of computers in our courses. This proved to be a very wise endeavour! 
The group is based in the Institute of Educational Technology with founder members including academics from Psychology, and the Education, Mathematics and Science Faculties, the then Student Computing Services and the staff based in regional offices. The original vision of a group with a strong international reputation for research excellence and with a mission to help deliver better learning experiences for students, has persisted and flourished.

The group understood that a large cohort of PhD students would be vital for the development of a research community so I offer a special acknowledgment both to current $\mathrm{PhD}$ students and to all the past $\mathrm{PhD}$ students who are the lifeblood of the group.

Thanks to the $\mathrm{PhD}$ programme and the work of various research staff over the years, the group has had an enviable record of external funding for research, well cited publications and well documented contributions to the success of The Open University in the various UK research assessment exercises.

As the chapters of this book demonstrate, the group is a key influencer in the research and development of educational technology worldwide. The members of the group have contributed to theory development, been technological innovators and conducted very large scale teaching experiments. The group's unique position comes from supporting and being embedded in a University whose raison d'etre derives from the application of educational technology in distance education. 